Brief Communication

\title{
Clinical Profile and Outcome of Pediatrics Tetanus: The Experience of a Tertiary Hospital in Ethiopia
}

\section{Henok Tadele ${ }^{1 *}$}

\section{ABSTRACT}

BACKGROUND: Tetanus is an acute vaccine preventable illness manifested by neuromuscular dysfunction due to a potent exotoxin, tetanospasmin produced by Clostridium tetani. It is a common health problem in developing countries like Ethiopia. The aim of this study was to assess clinical profile and outcome of Pediatrics tetanus in a referral hospital, South Ethiopia.

METHODS: This is a retrospective cross-sectional study of medical records of 24 Pediatric tetanus patients who were admitted from July 2014 to June 2016 to the Pediatrics Department of Hawassa University Comprehensive Specialized Hospital, Hawassa-Ethiopia. Tetanus was diagnosed clinically. Data were entered and analyzed using SPSS statistical software.

RESULTS: The median age at diagnosis was 8 years with 19 (79.2\%)of the study subjects being males. There were 3 male neonatal tetanus cases with 2 deaths. From post-neonatal cases, only 8(38.1\%) were fully vaccinated for infant Expanded Period of Immunization (EPI). Booster vaccination with TT (tetanus toxoid) was only given to $5(29.4 \%)$ of discharged patients. Trauma was common in above 5 years of age and documented in 19(79.2\%) of patients. All tetanus cases were generalized type with mild, moderate and severe grades comprising 7(29.2\%), 8(33.3\%), $7(29.2 \%)$ and $2(8.3 \%)$ respectively. Case fatality rate was $29.2 \%$ (7) with more deaths in higher grades. Respiratory failure 6(85.7\%), and aspiration pneumonia 1(14.3\%) were causes of death.

CONCLUSION: In this study, case fatality rate was high. Hence, health promotion with scale-up of EPI for infant tetanus immunization and large scale studies to provide support for booster vaccination schedules are recommended.

KEYWORDS: Profile, outcome, tetanus, children, Ethiopia

\section{INTRODUCTION}

Tetanus, a vaccine preventable disease, is an acute illness manifested by neuromuscular dysfunction due to a potent exotoxin, tetanospasmin produced by Clostridium tetani. Tonic spasms of the skeletal muscles with paroxysmal contractions are the typical presentations; lockjaw is the initial symptom (1). Tetanus is a clinical diagnosis. Neonatal cases are said to be confirmed if an infant with

DOI: http://dx.doi.org/10.4314/ejhs.v27i5.14 
normal ability to suck and cry in the first 2 days presents with failure to suck between 3 and 28 days of life with rigidity or spasms. Tetanus is classified as localized, cephalic and generalized (2-3).

Globally, a total of 56,743 deaths were reported due to tetanus in $2015: 19,937$ deaths occurred in neonates and 36,806 deaths occurred after the neonatal period. From all neonatal tetanus deaths, $45 \%$ and $44 \%$ occurred in South Asia and sub-Saharan Africa respectively. Sixty-seven $(67 \%)$ of the sub-Saharan neonatal deaths have happened in eastern sub-Saharan Africa. The case fatality rates (CFR) of tetanus vary from $10-70 \%$, the highest occurring in developing countries. Availability of intensive care unit reduces CFR to 10-20\%(4-6).

Principles of management of tetanus cases include admission to dark and quiet room, muscle spasm and rigidity control, autonomic dysfunction control, ventilator support when needed, neutralization of tetanus toxin ,wound management, antibiotics administration and prevention of recurrence with booster vaccination. Benzodiazepines are still the corner stone for sedation and spasm control while magnesium sulfate is also currently recommended $(3,7)$. Infant tetanus vaccination followed by booster doses and proper wound management are disease prevention strategies (8-9).

There is scarcity of studies on Pediatrics tetanus from Sub-Saharan Africa and Ethiopia particularily. Hence, this study was conducted to analyze clinical characteristics and outcome of Pediatrics tetanus cases admitted to Hawassa University Comprehensive Specialized Hospital (HUCSH).

\section{METHODS}

Study setting, design, period and subjects: This is a retrospective cross sectional study of medical records of 24 Pediatric tetanus patients who were admitted from July 2014 to June 2016 to the Pediatrics Department of HUCSH, the referral hospital for Southern Nations and Nationalities Regional State, Hawassa, Ethiopia. Medical records of patients were retrieved from medical records office and studied. Tetanus was diagnosed clinically and classified into localized, cephalic and generalized types. Severity was graded by Ablett classification into mild, moderate and severe (10).

Data collection and analysis: Data was collected from medical records of patients by using a data collection sheet. Clinical and demographic data including age, sex, expanded period of immunization (EPI) status, time of onset, outcome etc were collected. All data were entered, cleared and analyzed using SPSS (statistical package for social sciences) version 20. Descriptive statistics was used to present data.

Ethical approval: Ethical approval was obtained from the Institutional Review Board of the College of Medicine and Health Sciences, Hawassa University, Hawassa, Ethiopia.

\section{RESULTS}

Demographic and clinical profile data: The median age at diagnosis was 8 years with range from 3 days to 13 years. From documented cases, 19(79.2\%) were males. The majority of patients were aged above 5 years. There were 3 male neonatal tetanus cases, and one of them had associated gastroschisis. For post neonatal cases, infant (EPI) vaccination status was complete, incomplete, unknown and not vaccination in $8(38.1 \%), \quad 2(9.5 \%), \quad 8(38.1 \%)$ and $3(14.3 \%)$ respectively. Booster vaccination with TT (tetanus toxoid) was only given to $5(29.4 \%)$ of discharged patients (Table 1). Trauma or portal of entry was documented in 19(79.2\%) of patients. Trauma was common above 5 years of age, and tungiasis was documented in 5 cases (Table 2). All patients had generalized tetanus. Mild, moderate and severe grades of tetanus comprised 7(29.2\%), 8(33.3\%), $7(29.2 \%)$ and $2(8.3 \%)$ respectively according to Ablett classification (Table 3)

Dark room isolation, diazepam and chlorpromazine as muscle relaxants, debridement (for selected cases), pencillin $\mathrm{G}$ or metronidazole antibiotic and tetanus antitoxoid were given for all patients as a standard of care. Only one patient had tracheostomy and was admitted to the general intensive care unit (ICU).

DOI: http://dx.doi.org/10.4314/ejhs.v27i5.14 
Table 1: Demographic and clinical data of Pediatrics tetanus at HUCSH, 2014-2016

\begin{tabular}{|c|c|c|}
\hline Variable & Frequency(N) & Percentage $(\%)$ \\
\hline \multicolumn{3}{|l|}{ Age (years) } \\
\hline$<5$ & 5 & 20.8 \\
\hline $5-10$ & 10 & 41.7 \\
\hline $10-13$ & 9 & 37.5 \\
\hline \multicolumn{3}{|l|}{ Sex } \\
\hline Male & 19 & 79.2 \\
\hline Female & 5 & 20.8 \\
\hline \multicolumn{3}{|l|}{ Incubation period in days $(n=19)$} \\
\hline$<7$ & 3 & 15.8 \\
\hline $7-14$ & 7 & 36.8 \\
\hline $14-28$ & 5 & 26.3 \\
\hline$>28$ & 4 & 21.1 \\
\hline \multicolumn{3}{|l|}{ Time of onset in days $(\mathrm{n}=19)$} \\
\hline$<3$ & 6 & 31.6 \\
\hline $3-7$ & 6 & 31.6 \\
\hline$\geq 7$ & 7 & 36.8 \\
\hline \multicolumn{3}{|l|}{ Maternal TT vaccination- Neonatal cases } \\
\hline One time & 0 & 0 \\
\hline Two times and more & 2 & 66.7 \\
\hline None & 1 & 33.3 \\
\hline \multicolumn{3}{|l|}{ EPI- Post neonatal } \\
\hline Complete & 8 & 38.1 \\
\hline Incomplete & 2 & 9.5 \\
\hline Unknown & 8 & 38.1 \\
\hline Unvaccinated at all & 3 & 14.3 \\
\hline \multicolumn{3}{|l|}{ Outcome } \\
\hline Survived & 15 & 62.5 \\
\hline Died & 7 & 29.2 \\
\hline Discharged against medical advise & 2 & 8.3 \\
\hline \multicolumn{3}{|l|}{ Cause of death $(\mathrm{N}=7)$} \\
\hline Aspiration Pneumonia & 1 & 14.3 \\
\hline Respiratory failure/ uncontrolled spasm & 6 & 85.7 \\
\hline \multicolumn{3}{|l|}{ Booster vaccination on discharge $(\mathrm{N}=17)$} \\
\hline Yes & 5 & 29.4 \\
\hline No & 12 & 70.6 \\
\hline
\end{tabular}

From the neonatal cases, one was born at home, and there were 2 neonatal deaths. There was no history of umbilical manipulation or traditional procedure done at home in neonatal cases. From all admitted cases, 15(62.5\%), 7(29.2\%), and $2(8.3 \%)$ had survived, died and were discharged against medical advice respectively. Causes of deaths were respiratory failure , $6(85.7 \%)$ and aspiration pneumonia, $1(14.3 \%)$. The majority of the patients with mild to moderate severity grades had survived (Table 3 ). 
Table 2: Type of documented inciting injury or portal of entry in Pediatrics tetanus at HUCSH, 2014-2016 $(n=19)$.

\begin{tabular}{llll}
\hline Posible entry & $<$ 5years old & $5-10$ years old & $10-13$ years old \\
& $\mathrm{N}=2$ & $\mathrm{~N}=9$ & $\mathrm{~N}=8$ \\
\hline Metallic material & 1 & 1 & 3 \\
Wooden material & 0 & 3 & 3 \\
Animal excreta & 0 & 2 & 1 \\
Tungiasis & 1 & 3 & 1 \\
\hline
\end{tabular}

Table 3: Ablett tetanus severity grade, outcome and hospital stay in pediatrics tetanus atHUCSH, 20142016

\begin{tabular}{ccl}
\hline Variable & Frequency(N) & Percentage (\%) \\
\hline Ablett severity grade & 7 & 29.2 \\
I & 8 & 33.3 \\
II & 7 & 29.2 \\
III & 2 & 8.3 \\
IV & & \\
Outcome & 6 & 40 \\
Survived(n=15) & 6 & 40 \\
I & 3 & 20 \\
II & 0 & 0 \\
III & & \\
IV & 1 & 14.3 \\
Died(n=7) & 0 & 0 \\
I & 4 & 57.1 \\
II & 2 & 28.6 \\
III & 0 & \\
IV & 0 & 0 \\
Discharge against medical advice $(\mathbf{n}=\mathbf{2})$ & 100 \\
I & 2 & 0 \\
II & 0 & 0 \\
III & 0 & 29.2 \\
IV & 7 & 29.2 \\
Hospital stay in days & 7 & 33.3 \\
< 7 & 8 & 8.3 \\
$\mathbf{7 - 1 4}$ & 2 & \\
14-28 & & \\
>28 & &
\end{tabular}

\section{DISCUSSION}

Tetanus has remained a public health problem in developing countries with high case fatality rates. Efforts of neonatal, childhood and maternal elimination through vaccination have faced challenges in these parts of the world due to low health awareness, shortage of human and material resources and poor health seeking behaviour for trauma. Due to the very nature of tetanus, hospital based studies are found to be an effective means for collecting information on the epidemiologic and clinical data on neonatal and childhood

DOI: http://dx.doi.org/10.4314/ejhs.v27i5.14 
tetanus, and also for evaluating the impact of immunization programs (11-13).

In this study, children aged 5 years and above were found to be highly affected with a male predominance. This could be due to disappearance of protection from infant tetanus immunization and tendency of boys to engage in outdoor and rough competitive games. This is in agreement with other similar studies done in developing countries(8,14-17).

In this tudy, trauma is documented to be the most common portal of entry in $19(79.2 \%$ ) of patients. This could be explained by the high chance of ignoring Pediatric trauma and lack of provision of tetanus prophylaxis for healthcare seeking patients.This finding is higher than the finding from studies done in Nigeria, India and Nepal but comparable with a study done in Senegal. Differences could be explained by the differences in number of participants and Pediatric age range included in the studies (15-16,18-19).

In this study, only $8(38.1 \%)$ of cases were fully vaccinated according to EPI schedule, and only $5(29.4 \%)$ of discharged patients received TT vaccine on discharge. This could be explained by the low national EPI coverage, low awareness among professionals and lack of national policy on TT booster vaccination. Tetanus will not offer a lifelong immunity.This finding is consistent with the Ethiopian demographic survey report and other studies $(8,18,20)$.

In this study, it was found that the majority of patients had mild and moderate tetanus and outcome was poor in higher grades. Case fatality rate was $29.2 \%$, and the most common cause of death was respiratory failure secondary to uncontrolled spasm. This could be due to poor escalation of muscle relaxants and lack of Pediatric ICU care, a service which is limited in our hospital. This finding is comparable with findings of other similar studies $(16,18,21)$.

The main limitation of this study is lack of more detailed clinical information and statistical analysis on factors affecting mortality. There is a need for better documentation and medical records keeping. However, this study provides clinical profile and outcome of Pediatrics tetanus in HUCSH which serves as baseline information. It can also be used for planning targeted prevention strategies in the study and similar settings.

In conclusion, this study has documented high case fatality rates in Pediatric tetanus in the study area. Closer follow-up of patients to identify the progress of severity assists in identifying cases that require respiratory support and drug escalation. Hence, health promotion with scale up of EPI for infant tetanus immunization and large scale studies to provide support for booster vaccination schedules are recommended.

\section{ACKNOWLEDGEMENT}

I would like to thank all health professionals who cared for the patients.

\section{REFERENCES}

1. Itzhak Brook. Current concepts in the management of Clostridium tetani infection. Expert Review of Anti-infective Therapy 2008; 6(3): 327-336.

2. World Health Organization. WHOrecommended standards for surveillance of selected vaccine-preventable diseases. Vaccines and biologicals 2008; 22-27.

3. Stephen S.Aron.2011. Tetanus (Clostridium tetani). In:Robert M.Kliegman, Bonita F.Stanton, Joseph W.St. Gemme III,Nina F.Schor, Richard E.Behrman eds. Nelson Textbook of Pediatrics.19 $9^{\text {th }}$ edition. Philadelphia,Elsevier co., 2011; 991-994.

4. Li Liu, Shefali Oza, Dan Hogan et al. Global, regional, and national causes of under-5 mortality in 2000-15: an updated systematic analysis with implications for sustainable development goals. Lancet 2016; 388(10063): 3027-35.

5. Martha H Roper, Jos H Vandelaer, François L Gasse. Maternal and neonatal tetanus. The Lancet 2007; 370(9603): 1947-1959.

6. Kyu HH, Mumford JE, Barber RM etal. Mortality from tetanus between 1990 and 2015: findings from the global burden of disease study 2015. BMC Public Health 2017; 17(1):179.

7. Chaturaka Rodrigo, Deepika Fernando,Senaka Rajapakse. Pharmacological management of

DOI: http://dx.doi.org/10.4314/ejhs.v27i5.14 
tetanus: an evidence-based review. Critical Care 2014;18:217.

8. Yohannes Woubishet Woldeamanuel. Tetanus in Ethiopia: unveiling the blight of an entirely vaccine-preventable disease. Curr Neurol Neurosci Rep. 2012; 12(6):655-665.

9. World Health Organization. Tetanus vaccines: WHO position paper- February 2017. Weekly epidemiological record, 2017.

10. Ablett JJL. Analysis and main experiences in 82 patients treated in the Leeds tetanus unit. In: Ellis $\mathrm{M}$, ed. Symposium on tetanus in Great Britain. Boston Spa, UK: National Lending Library, 1967; 1-10.

11. Bwire R, Kawuma HJS. Hospital based study on neonatal tetanus, Buluba Hospital, 19851989. J Trop Med Hyg 1992; 95: 62-66.

12. Amanuel Amare, Yilma Melkamu ,Desalew Mekonnen. Tetanus in adults: Clinical presentation, treatment and predictors of mortality in a tertiart hospital in Ethiopia. Journal of the Neurol Sciences 2012;317(1-2): 62-65.

13. Yohannes Woubishet Woldeamanuel, Adel T.Andemeskel, Kwam Kyei, Meheret W.Woldeamanuel, Woubishet Woldeamanuel. Case fatality of adult tetanus in Africa: Systematic review and meta-analysis. $J$ Neurol Sci. 2016 ; 368:292-9.

14. Faizia Naseem Ahmed, Imtiaz Ahmad Mahar,Fehmina Arif. Two years' study of Tetanus cases in a Paediatric Intensive Care Unit. Pak J Med Sci 2016 , 2016;32(3):641645.

15. Prakash Poudel, Rupa Rajbhandari Singh, S Raja, S Budhathoki. Pediatric and neonatal tetanus: a hospital based study at eastern Nepal. Nepal Med Coll J 2008; 10(3): 170175.

16. T. Mondal, S. Aneja,A. Tyagi,Prashant Kumar,D. Sharma. A Study of childhood tetanus in post-neonatal age group in Delhi. Indian Pediatr. 1994; 31(11):1369-72.

17. Solomon Amsalu, Sileshi Lulseged. Tetanus in a children's hospital in Addis Ababa: review of 113 cases. Ethiop Med J. 2005; 43(4):23340.

18. Olusola Adetunji Oyedeji, Francis Fadero, Victor Joel-Medewase, Peter Elemile, Gabriel Ademola Oyedeji. Trends in neonatal and post-neonatal tetanus admissions at a Nigerian teaching hospital. J Infect Dev Ctries 2012; 6(12):847-853

19. Moussa Seydi, M Soumaré,Eudes GbangbaNgai etal.Current aspects of pediatric and adult tetanus in Dakar.M $\tilde{A} \odot$ decine et Maladies Infectieuses 2005; 35(1):28-32

20. Central Statistical Agency (CSA) [Ethiopia] and ICF. 2016. Ethiopia Demographic and Health Survey 2016: Key Indicators Report. Addis Ababa, Ethiopia, and Rockville, Maryland, USA. CSA and ICF.

21. Altaf Ahmed Talpur, Kashif Ali Channar, Tufail Ahmed Balouch, Bhesham Kumar, Akmal Jamal. patterns of morbidity and mortality among tetanus pateinst in Pakistan. Med. Channel 2016;22(3): 6-12. 